\title{
The Malnutritional Status of the Host as a Virulence Factor for New Coronavirus SARS-CoV-2
}

\begin{abstract}
Matteo Briguglio ${ }^{1 \star}$, Fabrizio Ernesto Pregliasco ${ }^{2,3}$, Giovanni Lombardi ${ }^{4,5}$, Paolo Perazzo ${ }^{6}$ and Giuseppe Banfi ${ }^{1,7}$

${ }^{1}$ IRCCS Orthopedic Institute Galeazzi, Scientific Direction, Milan, Italy, ${ }^{2}$ Health Management, IRCCS Orthopedic Institute Galeazzi, Milan, Italy, ${ }^{3}$ Department of Biomedical Sciences for Health, University of Milan, Milan, Italy, ${ }^{4}$ Laboratory of Experimental Biochemistry and Molecular Biology, IRCCS Orthopedic Institute Galeazzi, Milan, Italy, ${ }^{5}$ Department of Athletics, Strength and Conditioning, Poznań University of Physical Education, Poznań, Poland, ${ }^{6}$ Post-operative Intensive Care Unit \& Anesthesia, IRCCS Orthopedic Institute Galeazzi, Milan, Italy, ${ }^{7}$ Faculty of Medicine and Surgery, Vita-Salute San Raffaele University, Milan, Italy
\end{abstract}

Keywords: nutritional status, coronavirus, SARS-CoV-2, COVID-19, infections, virulence, host pathogen interactions, quality of health care

\section{THE SPILL OUT OF SARS-CoV-2}

OPEN ACCESS

Edited by:

Zisis Kozlakidis,

International Agency for Research on

Cancer (IARC), France

Reviewed by:

Andreas Nüssler,

Tübingen University

Hospital, Germany

*Correspondence:

Matteo Briguglio

matteo.briguglio@grupposandonato.it

Specialty section:

This article was submitted to Infectious Diseases - Surveillance,

Prevention and Treatment, a section of the journal

Frontiers in Medicine

Received: 20 March 2020 Accepted: 03 April 2020

Published: 23 April 2020

Citation:

Briguglio M, Pregliasco FE, Lombardi G, Perazzo P and Banfi G (2020) The Malnutritional Status of the

Host as a Virulence Factor for New

Coronavirus SARS-CoV-2.

Front. Med. 7:146.

doi: 10.3389/fmed.2020.00146
An outbreak of viral pneumonia was reported in Wuhan, China, at the end of December 2019, and subsequent sample analyses discovered the involvement of a new strain of coronavirus (SARS-CoV-2), which belongs to the same family of single-stranded enveloped RNA viruses that caused the emergences of SARS-CoV in 2003 and MERS-CoV in 2012. Symptoms of COVID-19 (SARS-CoV-2 syndrome) may occur within 2-14 days after exposure and can lead to difficulties in cilium beating of airway cells and to alveolar damage (1). Infected patients experience mild to severe manifestations, such as fever, dry cough, dyspnoea, abdominal pain, and diarrhea. Most cases resolve rapidly, but the infection can still be fatal in about $3 \%$ of cases (2). Much like MERS or the coronavirus that infects pigs, the enteric affections can be prominent $(3,4)$, possibly leading to the loss of absorptive potential. Just a few weeks after its discovery, the COVID-19 has been considered a serious worldwide threat. At the time of writing, Italy is the worst-hit country with 97,689 confirmed cases and 10,781 total deaths (WHO COVID-19 Situation report 70, 30 March 2020). Preliminary data suggest that male older adults and subjects with immune dysfunctions might be more susceptible to the worse viral disease, but there is a need to further investigate the virulence factors. One of the factors most discussed is the malnutritional status of the host, but most of the beliefs are anecdotal. On the other hand, strong evidence supports the notion that any infection outcome is highly dependent on the nutritional status of the host since viruses subject the host's body to a considerable energetic effort to sustain costly defenses. If a previous malnutritional status exists, or if no nutritional care is provided, the host easily encounters the emptying of body reservoirs with increased harm caused by the virus. A possible link between the nutritional status of the host, the virulence of SARS-CoV-2, and the clinical outcome of COVID-19 needs to be discussed.

\section{THE HOST ABILITIES AGAINST INFECTIONS}

A distinction should be made between the susceptibility to developing a symptomatic infection, from now on referred to as "first-line host ability," and the fighting potential, referred to as "secondline host ability." From the perspective of infectious diseases, the first-line host ability is expressed by its immunocompetence, which is in turn uttered by the nutrient intake-requirement balance. 
A malnutritional status refers to any balance deviation, including the general excess, insufficiency, or single-nutrient deficits. The second-line host ability is expressed by the endurance or ability to persist in fighting the infection. For SARS-CoV-2, it can be assumed that the healthier is the nutritional status of the host, the higher are the first-line host abilities, the lower is the susceptibility to COVID-19, the lower is the virulence of SARS-CoV-2, and, thus, the longer the host will endure in the fight. This transitive relation is not necessarily assumable for all pathogens. Concerning parasitic infections, well-nourished subjects may offer a wealthier environment to developing parasites than malnourished individuals (5), but they can also afford investments to endure in the fight, still having the upper hand on the infection outcome. Whatever the nature of the susceptibility to viral infections, second-line host abilities are based not only on the ability to support an adequate immune response but rely also on the body's ability to support an extensive controlled catabolic cytokine flow. Once infected, the nutritional reservoirs have been shown to influence outcomes in many diseases, comprising the immunodeficiency virus, the influenza virus, or pneumonia $(6,7)$. The within-host reservoirs depend on the external environment (8); the highest resources should exist in hosts living in the wealthiest environments. Regrettably, even the wealthiest countries present high rates of deficiency syndromes.

\section{THE HOST REACTIONS AGAINST SARS-CoV-2}

Both first- and second-line host abilities are necessary to heal from SARS-CoV-2 infection. Once the virus gets inside the airways through respiratory droplets, it infects local cells and evokes the host immune response. Mild symptoms of COVID19 may be triggered by a local inflammation limited to the lungs that should resolve quickly. Asymptomatic individuals have been reported to have no high fever (no increased expenditure) and no SARS-CoV-2-derived gastrointestinal symptoms that could have affected dietary intakes (9). The immunocompetent host response in non-severe cases recruits immune cell populations, such as CD4/CD8 $\mathrm{T}$ cells and antibody-secreting cells together with specific immunoglobulin (Ig)M and $\operatorname{IgG}$ SARS-CoV-2-binding antibodies (10). Basic treatments comprise intravenous antibiotics, antiviral therapy, antifungal medications, systemic glucocorticoids, and interferon. In cases with comorbid conditions, such as cardiovascular diseases and diabetes (11), there may be a basal immune dysfunction since the elderly and sick are often malnourished. If the immunoincompetence fails to control the SARS-CoV-2 or the virus replicates faster than expected, a severe inflammatory condition then arises and spreads to other organs together with the virus. Worsened patients show lymphopenia, cytokine storm (12), and multiple organ failure (13). These biochemical signs together with the decrease in CD4 T cells are a common feature in patients with COVID-19 and might be a critical virulence factor (14). The intestines may be particularly suitable for viral proliferation, as gut tropism in not unusual for coronaviruses. The host's ability to endure may depend on energy-nutrient intakes, which may be hampered by gastrointestinal symptoms and the hypermetabolism. Higher rates of nausea, vomiting, and diarrhea were observed in severe COVID-19 patients, which appear to be more likely to have anorexia (15). The prevalence of malnutrition (probably hyponutrition) was 3\% among the deceased vs. $0 \%$ among survivors (16). Healthy body reservoirs, early adaptive immune potential, and nutritional care may indeed be associated with better outcomes from COVID-19.

\section{THE DISABILITIES OF MALNOURISHED INDIVIDUALS DURING INFECTIONS}

"Malnutrition is the primary cause of immunodeficiency worldwide" (17) and affects both the innate and adaptive immune responses (18) that should inhibit viral proliferation. Chronic diseases, which have been recognized as virulence factors for severe COVID-19, are often comorbid with protein-energy malnutrition (also known as disease-related malnutrition), which is known to impair immune cell activation $(19,20)$, thus allowing longer viral persistence and increased trafficking of inflammatory cells to lungs (21). The basal immunoincompetence (22) can be further aggravated upon infection (23). Insufficient protein intakes may lead to nutrition-related sarcopenia. The concomitant excess of adiposity has been defined as "sarcopenic obesity" and carries issues of both conditions. Increased body fat sustains a systemic low-grade inflammation, primarily because of the leptin-induced CD4 T-cell function that increases autoimmunity (24). Basal T cells are more prone to exhaustion in obese subjects (25) who may therefore be more exposed to SARS-CoV-2 proliferation, as occurs with the herpes simplex virus (26). In fact, exhausted $\mathrm{T}$ cells exhibit poor effector function, proliferation, and cytotoxicity (27). During the 2009 pandemic caused by the influenza A (H1N1)pdm09 virus, obesity was found to be a virulence factor for a more severe outcome (28) much like for respiratory infections (29). Micronutrient deficiencies are also a rising issue among malnourished subjects. Vitamins have a role in the proper functioning of both the innate and adaptive immune responses, with vitamin $\mathrm{D}$ and $\mathrm{A}$ being the main actors (30). For instance, vitamin D is important for the proper functioning of antibody-secreting cells (31) and vitamin A sustains T-cell proliferation (32). The immune dysfunction in hyponutritional statuses can be linked to these deficiencies alike the excess of feeding, which is often associated with a monotonous diet and therefore low in sources of vitamins. A plethora of other micronutrients is known to have a role in the immunocompetence of the host against infections, including B vitamins, vitamin $\mathrm{C}$, vitamin $\mathrm{E}$, iron, selenium, and zinc (33), with malnourished individuals often suffering from the most. Malnutritional statuses carry less endurance to survive from severe COVID-19. Hypermetabolism and excessive nitrogen loss are factors known to be associated with infective states, and malnourished individuals are therefore disadvantaged because of the lesser body reserves. For instance, infected mice fed with lesser proteins, iron, and zinc than the optimal requirements were 
found to encounter a significant decrease in both weight and effector CD4 T cells vs. normal nourished animals (34).

\section{NUTRITIONAL CARE IN COVID-19}

If the patient had a good nutritional status before infection, then body reserves and basal dietary intake would assure the coverage of costly immune defenses in mild conditions. If a malnutritional status was present, which is very common among older adults, then increased requirements should be provided since the infection is expected to be protracted (35). Mild cases might experience a loss of appetite often accompanied by insomnia, nausea, vomiting, and reduced oral intakes, thus further compromising the basal poor nutritional. Even subacute malnourished patients are more prone to adverse events than healthy counterparts upon hospital admission (36). Once mechanical ventilation, extracorporeal membrane oxygenation, and renal-replacement therapy have been introduced, parenteral nutrition is the sole option. Severe cases with fever have increased energy expenditure and requirements for each degree of temperature increase. The usage of muscle-derived amino acids for immune protein synthesis increases whole-body glucose and nitrogen excretion, with a significant energy cost of immune upregulation (37). Unfortunately, the increased adiposity of obese individuals is not effectively used during infections (38), and the breakdown of the already poor muscle mass can have severe consequences. Similar metabolic consequences are seen in older trauma patients, with the malnourished subjects being the most at risk of adverse clinical outcomes (39). If energy and protein requirements are met, then the emptying of body

\section{Malnutritional statuses as virulence factor for the SARS-CoV-2}

\section{Hyponutrition $\mathbb{W}$}

Mainly protein-energy malnutrition

Conditions possibly associated with increased virulence

Shortage diseases

Low body proteins (low intake)

Low immunoreactivity

Reduced $\mathrm{T}$ cell function

Increased IL-4 and IL-10

Vitamin A, D, and E deficiencies

Vitamin B deficiencies

Iron-deficiency anemia

Micronutrient deficiencies

\section{The structure of SARS-CoV-2}

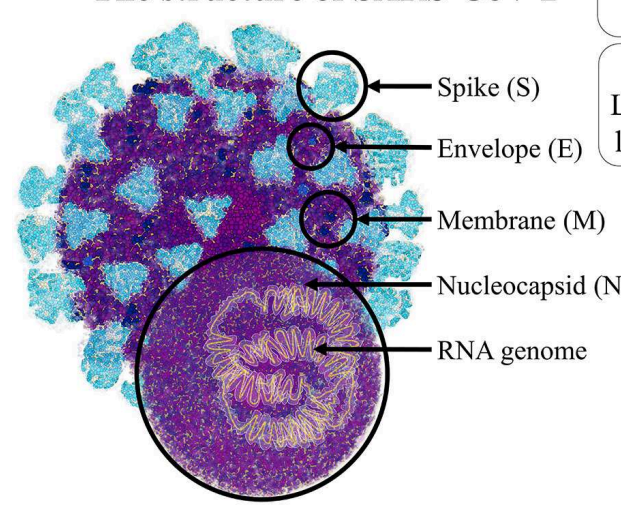

Respiratory droplets from infected person in close contact.

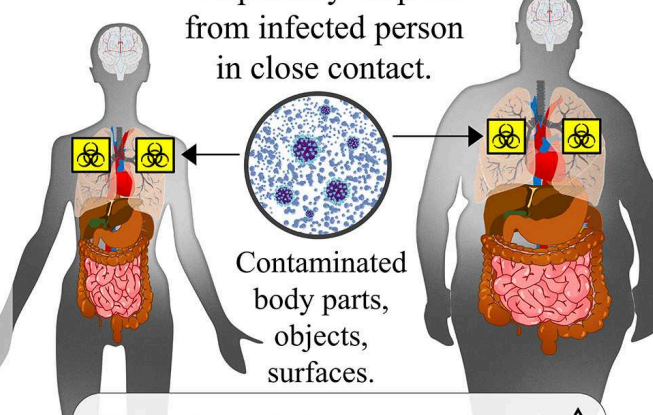

Most relevant virulence co-factor $\Delta$

Immune dysfunction (chronic - e.g., organ transplant, cancer- or transient - e.g., athlete after training-)

Increased susceptibility

Older age, comorbid conditions, polypharmacotherapy

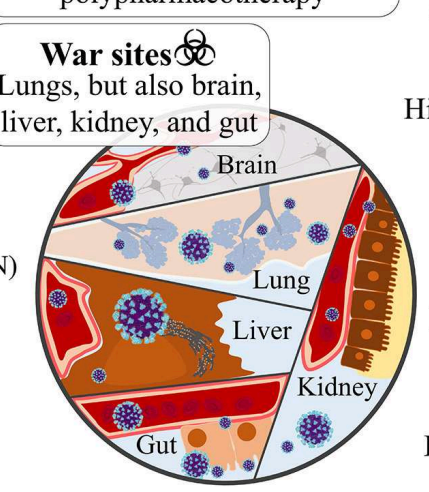

The nutritional implications that may experience patients with SARS-CoV-2

Symptom/sign

High body temperature

Tachypnea

Cytokine storm

Diarrhea

Abdominal pain

Lethargy, anorexia

Social isolation

Mental distress

Reduced movement
Hypernutrition $\pi$

Mainly sarcopenic obesity

Conditions possibly associated with increased virulence

Wellness diseases

Low body proteins (high sedentary)

Low-grade inflammation

Increased immunoreactivity

Exhaustion of T cells

Reduced IL-4 and IL-10

Vitamin A, D, and E deficiency

Vitamin B deficiencies

ron, zinc, and selenium deficiencies

\section{Nutritional effect}

Increased energy needs Increased energy expenditure Loss of body constituents Malabsorption Lack of appetite Reduced food supply Reduced food security Lack of desire to feed Loss of lean mass

FIGURE 1 | The SARS-CoV-2 virulence and the malnutritional status of the human host: immune-based dysfunctions in hypo- and hypernutrition. The severe acute respiratory syndrome coronavirus that was discovered in Hubei province, China, at the end of December 2019 (SARS-CoV-2) is a single-strand positive-sense RNA virus with the encoding potential of four structural proteins: the spike (S), the envelope $(E)$, the membrane $(M)$, and the nucleocapsid (N). It spreads through respiratory droplets of infected patients that can deposit on body parts and fomites. The basal immune dysfunction that exists in protein-energy malnutrition and sarcopenic obesity can make individuals more susceptible to SARS-CoV-2 contraction and affections. Other than the collapse of alveoli and respiratory failure, the coronavirus replication leads to systemic consequences in the brain, liver, kidneys, and gut. Once affected, malnourished individuals will have fewer body reservoirs and immune potential to fight for recovery. 
reservoirs may be avoided, and the immune response may be sustained. Once full-blown, COVID-19 patients should be supported with proper nutrition aimed at delivering adequate proteins (1.5-2.0 g/kg/day likely needed), energy (105-160 $\mathrm{kj} / \mathrm{kg} /$ day or $25-40 \mathrm{kcal} / \mathrm{kg} /$ day), vitamins, and trace elements. Nutrition should be titrated up to meet higher requirements because the delivery of the highest energy during the initial phase may be counterproductive. Guidelines for polymorbid patients should be followed (40-42). Partial isocaloric replacement of carbohydrates with lipids may be considered to reduce the production of $\mathrm{CO}_{2}$ by $30 \%$ per caloric unit (43).

\section{CONCLUSION}

In the current pandemic panorama of SARS-CoV-2, the link between nutrition and virulence takes a predictable turn. On one hand, many opportunists boast dietary plans against SARS$\mathrm{CoV}-2$, and, on the other hand, there is the sellout of dietary supplements that boost the immune system. In Italy, many instances of fake news have circulated on social networks, and many pharmacies have exposed signs that state: "Masks sold-out but vitamin C available." In these times of fear and confusion, speculations should be disciplined. Nonetheless, a greater understanding of the link between nutrition and SARSCoV-2 is needed, as the pathogen fitness may also depend on the host available resources (44). Future studies should focus on the transmission potential of malnutritional statuses. In the past, these conditions were suggested to negatively influence the transmission of alphaviruses to other hosts (45). Since most of infected cases are asymptomatic, the spreading of the virus is much easier than the previous coronaviruses (46). Yet, the risk of contracting SARS-CoV-2 does not depend on the individual's nutritional status but on the degree of contact with

\section{REFERENCES}

1. Zhu N, Zhang D, Wang W, Li X, Yang B, Song J, et al. A novel coronavirus from patients with pneumonia in China, 2019. N Engl J Med. (2020) 382:72733. doi: 10.1056/NEJMoa2001017

2. Guan W-J, Ni Z-Y, Hu Y, Liang W-H, Ou C-Q, He J-X, et al. Clinical characteristics of 2019 novel coronavirus infection in China. $N$ Engl J Med. (2020). doi: 10.1056/NEJMoa2002032

3. Zhou J, Huang F, Hua X, Cui L, Zhang W, Shen Y, et al. Inhibition of porcine transmissible gastroenteritis virus (TGEV) replication in mini-pigs by shRNA. Virus Res. (2010) 149:51-5. doi: 10.1016/j.virusres.2009.12.012

4. Mao R, Liang J, Shen J, Ghosh S, Zhu L-R, Yang H, et al. Implications of COVID-19 for patients with pre-existing digestive diseases. Lancet Gastroenterol Hepatol. (2020). doi: 10.1016/S2468-1253(20)30076-5. [Epub ahead of print].

5. Cornet S, Sorci G. Parasite virulence when the infection reduces the host immune response. Proc Biol Sci. (2010) 277:1929-35. doi: $10.1098 /$ rspb.2010.0138

6. Chandra RK. Nutrition, immunity and infection: from basic knowledge of dietary manipulation of immune responses to practical application of ameliorating suffering and improving survival. Proc Natl Acad Sci USA. (1996) 93:14304-7. doi: 10.1073/pnas.93.25.14304

7. Cressler CE, Nelson WA, Day T, McCauley E. Disentangling the interaction among host resources, the immune system and pathogens. Ecol Lett. (2014) 17:284-93. doi: 10.1111/ele.12229 the pathogen. Whether the coronavirus exposure develops into a true infection might contrariwise depend on the individual's first-line abilities, and, regrettably, malnutrition is a common occurrence that afflicts many older adults in China (47) and Italy (48), both having been heavily afflicted by the highest number of deaths. It is clear that the segment of population most at risk of SARS-CoV-2 infection is the elderly, with frailty (49) and older age (50) being well-known predictors of a negative outcome in acute care settings. Intensive clinical monitoring at admission with subsequent tailored nutritional care is needed for COVID-19 patients, especially those with co-existing chronic conditions or medications that could further aggravate the nutritional status (51). To conclude, there are several main nutritional issues to consider when fighting COVID-19 (see Figure 1 for details). A malnutritional status is associated with immune dysfunction. Malnourished individuals may be more susceptible to SARS-CoV-2 infection. Subjects with COVID-19 often become malnourished. Nutritional support is vital in severe COVID-19 patients.

\section{AUTHOR CONTRIBUTIONS}

$\mathrm{MB}$ formulated the hypothesis and wrote the first draft of the manuscript. FP, GL, PP, and GB revised the first draft and contributed to manuscript sections. All authors contributed to manuscript revision, read, and approved the submitted version.

\section{ACKNOWLEDGMENTS}

None that interests colleagues, institutions, or agencies in supporting this hypothesis. Yet all authors thank all the health workers and volunteers in Italy at the front lines of the fight against this SARS-CoV-2.

8. Mideo N, Alizon S, Day T. Linking within- and between-host dynamics in the evolutionary epidemiology of infectious diseases. Trends Ecol Evol. (2008) 23:511-7. doi: 10.1016/j.tree.2008.05.009

9. Hu Z, Song C, Xu C, Jin G, Chen Y, Xu X, et al. Clinical characteristics of 24 asymptomatic infections with COVID-19 screened among close contacts in Nanjing, China. Sci China Life Sci. (2020). doi: 10.1007/s11427-020-1661-4. [Epub ahead of print].

10. Thevarajan I, Nguyen THO, Koutsakos M, Druce J, Caly L, van de Sandt $\mathrm{CE}$, et al. Breadth of concomitant immune responses prior to patient recovery: a case report of non-severe COVID-19. Nat Med. (2020) 16:1-3. doi: 10.1038/s41591-020-0819-2

11. Wang D, Hu B, Hu C, Zhu F, Liu X, Zhang J, et al. Clinical characteristics of 138 hospitalized patients with 2019 novel coronavirus-infected pneumonia in Wuhan, China. JAMA. (2020). doi: 10.1001/jama.2020.1585. [Epub ahead of print].

12. Huang C, Wang Y, Li X, Ren L, Zhao J, Hu Y, et al. Clinical features of patients infected with 2019 novel coronavirus in Wuhan, China. Lancet. (2020) 395:497-506. doi: 10.1016/S0140-6736(20)30183-5

13. Chen N, Zhou M, Dong X, Qu J, Gong F, Han Y, et al. Epidemiological and clinical characteristics of 99 cases of 2019 novel coronavirus pneumonia in Wuhan, China: a descriptive study. Lancet. (2020) 395:507-13. doi: 10.1016/S0140-6736(20)30211-7

14. Zhang C, Shi L, Wang FS. Liver injury in COVID-19: management and challenges. Lancet Gastroenterol Hepatol. (2020) 5:428-30. doi: 10.1016/S2468-1253(20)30057-1 
15. Mo P, Xing Y, Xiao Y, Deng L, Zhao Q, Wang H, et al. Clinical characteristics of refractory COVID-19 pneumonia in Wuhan, China. Clin Infect Dis. (2020). doi: 10.1093/cid/ciaa270. [Epub ahead of print].

16. Yang X, Yu Y, Xu J, Shu H, Xia J, Liu H, et al. Clinical course and outcomes of critically ill patients with SARS-CoV-2 pneumonia in Wuhan, China: a single-centered, retrospective, observational study. Lancet Respir Med. (2020). doi: 10.1016/S2213-2600(20)30079-5

17. Katona P, Katona-Apte J. The interaction between nutrition and infection. Clin Infect Dis. (2008) 46:1582-8. doi: 10.1086/587658

18. Alwarawrah Y, Kiernan K, MacIver NJ. Changes in nutritional status impact immune cell metabolism and function. Front Immunol. (2018) 9:1055. doi: 10.3389/fimmu.2018.01055

19. Wing EJ, Magee DM, Barczynski LK. Acute starvation in mice reduces the number of $\mathrm{T}$ cells and suppresses the development of T-cell-mediated immunity. Immunology. (1988) 63:677-82.

20. Gerriets VA, MacIver NJ. Role of T cells in malnutrition and obesity. Front Immunol. (2014) 5:379. doi: 10.3389/fimmu.2014.00379

21. Taylor AK, Cao W, Vora KP, De La Cruz J, Shieh WJ, Zaki SR, et al. Protein energy malnutrition decreases immunity and increases susceptibility to influenza infection in mice. J Infect Dis. (2013) 207:501-10. doi: 10.1093/infdis/jis527

22. Gonzalez-Martinez H, Rodriguez L, Najera O, Cruz D, Miliar A, Dominguez A, et al. Expression of cytokine mRNA in lymphocytes of malnourished children. J Clin Immunol. (2008) 28:593-9. doi: 10.1007/s10875-0089204-5

23. Najera O, Gonzalez C, Toledo G, Lopez L, Ortiz R. Flow cytometry study of lymphocyte subsets in malnourished and well-nourished children with bacterial infections. Clin Diagn Lab Immunol. (2004) 11:577-80. doi: 10.1128/CDLI.11.3.577-580.2004

24. Procaccini C, De Rosa V, Galgani M, Carbone F, Cassano S, Greco D, et al. Leptin-induced mTOR activation defines a specific molecular and transcriptional signature controlling $\mathrm{CD} 4+$ effector $\mathrm{T}$ cell responses. $J$ Immunol. (2012) 189:2941-53. doi: 10.4049/jimmunol.1200935

25. Kado T, Nawaz A, Takikawa A, Usui I, Tobe K. Linkage of CD8(+) T cell exhaustion with high-fat diet-induced tumourigenesis. Sci Rep. (2019) 9:12284. doi: 10.1038/s41598-019-48678-0

26. Hoshino Y, Pesnicak L, Cohen JI, Straus SE. Rates of reactivation of latent herpes simplex virus from mouse trigeminal ganglia ex vivo correlate directly with viral load and inversely with number of infiltrating CD8+ T cells. J Virol. (2007) 81:8157-64. doi: 10.1128/JVI.00474-07

27. Schietinger A, Greenberg PD. Tolerance and exhaustion: defining mechanisms of $\mathrm{T}$ cell dysfunction. Trends Immunol. (2014) 35:51-60. doi: 10.1016/j.it.2013.10.001

28. Louie JK, Acosta M, Samuel MC, Schechter R, Vugia DJ, Harriman K, et al. A novel risk factor for a novel virus: obesity and 2009 pandemic influenza A (H1N1). Clin Infect Dis. (2011) 52:301-12. doi: 10.1093/cid/ciq152

29. Milner JJ, Beck MA. The impact of obesity on the immune response to infection. Proc Nutr Soc. (2012) 71:298-306. doi: 10.1017/S00296651120 00158

30. Mora JR, Iwata M, von Andrian UH. Vitamin effects on the immune system: vitamins A and D take centre stage. Nat Rev Immunol. (2008) 8:685-98. doi: $10.1038 /$ nri2378

31. Shirakawa AK, Nagakubo D, Hieshima K, Nakayama T, Jin Z, Yoshie O. 1,25-dihydroxyvitamin D3 induces CCR10 expression in terminally differentiating human B cells. J Immunol. (2008) 180:2786-95. doi: 10.4049/jimmunol.180.5.2786

32. Ertesvag A, Engedal N, Naderi S, Blomhoff HK. Retinoic acid stimulates the cell cycle machinery in normal $\mathrm{T}$ cells: involvement of retinoic acid receptor-mediated IL-2 secretion. J Immunol. (2002) 169:5555-63. doi: 10.4049/jimmunol.169.10.5555

33. Gombar AF, Pierre A, Maggini S. A review of micronutrients and the immune system-working in harmony to reduce the risk of infection. Nutrients. (2020) 12:236. doi: 10.3390/nu12010236

34. Pilotos J, Smith MR, Johnson CM, Campbell L, Ibitokou S, Stephens R, et al. Malnutrition decreases both effector and memory CD4 T cells in malaria infection. J Immunol. (2018) 200(Suppl.):52.39.

35. Mahalingam M, Moore JX, Donnelly JP, Safford MM, Wang HE. Frailty Syndrome and Risk of Sepsis in the REasons for Geographic And Racial
Differences in Stroke (REGARDS) Cohort. J Intensive Care Med. (2019) 34:292-300. doi: 10.1177/0885066617715251

36. Charlton K, Nichols C, Bowden S, Milosavljevic M, Lambert K, Barone L, et al. Poor nutritional status of older subacute patients predicts clinical outcomes and mortality at 18 months of follow-up. Eur J Clin Nutr. (2012) 66:1224-8. doi: $10.1038 /$ ejen.2012.130

37. Klasing KC. Nutritional aspects of leukocytic cytokines. J Nutr. (1988) 118:1436-46. doi: 10.1093/jn/118.12.1436

38. Berclaz PY, Benedek C, Jequier E, Schutz Y. Changes in protein turnover and resting energy expenditure after treatment of malaria in Gambian children. Pediatr Res. (1996) 39:401-9. doi: 10.1203/00006450-199603000-00005

39. Ihle C, Freude T, Bahrs C, Zehendner E, Braunsberger J, Biesalski HK, et al. Malnutrition - An underestimated factor in the inpatient treatment of traumatology and orthopedic patients: a prospective evaluation of 1055 patients. Injury. (2017) 48:628-36. doi: 10.1016/j.injury.2017.01.036

40. Gomes F, Schuetz P, Bounoure L, Austin P, Ballesteros-Pomar M, Cederholm $\mathrm{T}$, et al. ESPEN guidelines on nutritional support for polymorbid internal medicine patients. Clin Nutr. (2018) 37:336-53. doi: 10.1016/j.clnu.2017.06.025

41. Singer P, Blaser AR, Berger MM, Alhazzani W, Calder PC, Casaer MP, et al. ESPEN guideline on clinical nutrition in the intensive care unit. Clin Nutr. (2019) 38:48-79. doi: 10.1016/j.clnu.2018.08.037

42. Murthy S, Gomersall CD, Fowler RA. Care for critically ill patients with COVID-19. JAMA. (2020). doi: 10.1001/jama.2020.3633. [Epub ahead of print].

43. Askanazi J, Nordenstrom J, Rosenbaum SH, Elwyn DH, Hyman AI, Carpentier YA, et al. Nutrition for the patient with respiratory failure: glucose vs. fat. Anesthesiology. (1981) 54:373-7. doi: 10.1097/00000542-198105000-00005

44. Pike VL, Lythgoe KA, King KC. On the diverse and opposing effects of nutrition on pathogen virulence. Proc Biol Sci. (2019) 286:20191220. doi: $10.1098 /$ rspb.2019.1220

45. Weger-Lucarelli J, Carrau L, Levi LI, Rezelj V, Vallet T, Blanc H, et al. Host nutritional status affects alphavirus virulence, transmission, and evolution. PLoS Pathog. (2019) 15:e1008089. doi: 10.1371/journal.ppat.1008089

46. Wilder-Smith A, Chiew CJ, Lee VJ. Can we contain the COVID-19 outbreak with the same measures as for SARS? Lancet Infect Dis. (2020). doi: 10.1016/S1473-3099(20)30129-8

47. Lin YM, Wang M, Sun NX, Liu YY, Yin TF, Chen C. Screening and application of nutritional support in elderly hospitalized patients of a tertiary care hospital in China. PLoS ONE. (2019) 14:e0213076. doi: 10.1371/journal.pone.0213076

48. Bonetti L, Terzoni S, Lusignani M, Negri M, Froldi M, Destrebecq A. Prevalence of malnutrition among older people in medical and surgical wards in hospital and quality of nutritional care: a multicenter, cross-sectional study. J Clin Nurs. (2017) 26:5082-92. doi: 10.1111/jocn.14051

49. Bastoni D, Ticinesi A, Lauretani F, Calamai S, Catalano ML, Catania P, et al. Application of the sepsis-3 consensus criteria in a geriatric acute care unit: a prospective study. J Clin Med. (2019) 8:359. doi: 10.3390/jcm8030359

50. Sorbello M, El-Boghdadly K, Di Giacinto I, Cataldo R, Esposito C, Falcetta S, et al. The Italian coronavirus disease 2019 outbreak: recommendations from clinical practice. Anaesthesia. (2020). doi: 10.1111/anae.15049. [Epub ahead of print].

51. Briguglio M, Hrelia S, Malaguti M, Serpe L, Canaparo R, Dell'Osso $B$, et al. Food bioactive compounds and their interference in drug pharmacokinetic/pharmacodynamic profiles. Pharmaceutics. (2018) 10:277. doi: 10.3390/pharmaceutics 10040277

Conflict of Interest: The authors declare that the research was conducted in the absence of any commercial or financial relationships that could be construed as a potential conflict of interest.

Copyright (c) 2020 Briguglio, Pregliasco, Lombardi, Perazzo and Banfi. This is an open-access article distributed under the terms of the Creative Commons Attribution License (CC BY). The use, distribution or reproduction in other forums is permitted, provided the original author(s) and the copyright owner(s) are credited and that the original publication in this journal is cited, in accordance with accepted academic practice. No use, distribution or reproduction is permitted which does not comply with these terms. 